\title{
Research on the Training Mode Reform of Mathematical Education Professionals in Higher Vocational College under the Background of National Teacher Certification Examination
}

\author{
Peng Cao \\ Dept. of Mathematics and Physics \\ Qiongtai Teachers College \\ Haikou, China \\ lanyuan97@126.com
}

\author{
Ziqiang Luo \\ College of Information Science and Technology \\ Hainan Normal University \\ Haikou, China \\ 306003057@qq.com*Corresponding Author
}

\begin{abstract}
In the context of teacher certification examination system reform in China, considering the current situation in education and training of primary school teachers, this paper discussed the talent training mode reform of mathematical education professionals in higher vocational colleges. The reform including the talent training objectives, curriculum teaching system, talent training approach, and talent appraisal systems, may provide evidence and references for pre-service training for elementary school mathematics teachers.
\end{abstract}

Keywords-national teacher certification examination; mathematical education; higher vocational college; personnel training mode

\section{INTRODUCTION}

Pilot work of reform of Chinese teacher certification examination began at 2011, ten provinces were specified as pilot provinces in 2013, and then teacher certification examination was fully implemented in 2015[1]. The purpose of the pilot reform on the teacher certification examination, is to establish national teacher certification examination standards, to reform examination content to strengthen professional ethics, psychological literacy, teaching competencies and professional development potentials. Teacher certification examination system reform is being carried out in full swing at present.

Compared with the reform before, the scope of the exam content is more wide, reference materials are not specified, the difficulty of exam is greatly increased, and certification procedures are more strict. The written examination scores are effective for two years, and written examinations qualified in all subjects are prior to attending interview. Teacher certification can be applied for when one pass written exam and interview. In addition, some subjects also require student teaching internship experience.

Especially important is that after the introduction of a new teacher certification exam, students will no longer automatically receive teacher certification, but must also participate in the State exams. The reform of teacher certification examination brings forward new requirements about the training mode of primary school teachers. There are many gaps between traditional training mode and the new requirements, so we should conduct extensive and indepth research on the talent training mode of teachers' professional. It is suggested to call for a reform in the depth of China's mathematics teacher education so as to train university students to become teachers who are wellinformed, competent and thinking professionals[2].

Linked up with the national teacher certification examination system reform, to some extent there is a great practical significance to the talent training mode reform of mathematical education professionals in higher vocational colleges. The Junior College seeks to prepare teachers for junior and primary schools. Through in-depth reforms we can raise substantially the passing rate of students' teacher certification examination, improve students employment; can promote the courses construction of mathematics education professional, improve core competitiveness and sustainable development level of professional; can improve ability of running a school, carry out in a deep-going way of talent training mode about the cooperation between University and elementary school; can optimize talent training evaluation system, upgrade the overall quality of graduates, deliver outstanding primary school teachers for the country.

The reform including the talent training objectives, curriculum teaching system, talent training approach, and talent appraisal systems, may provide evidence and references for pre-service training for elementary school mathematics teachers. This article will discuss the above four aspects about the talent training mode reform of mathematical education professionals in higher vocational colleges.

\section{THE REFORM OF THE TRAINING OBJECTIVES OF MATHEMATICS EDUCATION MAJOR}

The objectives of talents training of mathematics education major in higher vocational colleges in our country talents are largely similar, to sum up, the general objective is to train qualified primary school teachers and administrators, specific objective is to hand over qualified teachers who capable of teaching and management in elementary school.

With the gradually establishment and improvement of national unification teacher certification examination, as well as changes in social demands, the goal to train qualified primary school teachers has not been able to adapt well to the current changes in the objective environment. The talent training goal should start with practical national standards, and focus on unified national standards. Overall objective 
will shift from training qualified primary school teachers to train outstanding primary school teachers.

\section{The Reform OF THE TEACHING System OF Mathematics Education Professional Course}

\section{A. Optimize the Curriculum, Integrate Smoothly into the Teacher Certification Examination}

1. Set curriculum according to the teacher certification examination

The junior college program curriculum is divided into compulsory modules and electives, and comprises four main areas of courses, namely, general culture courses, major courses, education courses and practicum. There is an urgent need for an effective balance in the distribution of time given to the learning of theories and principles and time for application and teaching strategies which are so necessary to the beginning teachers' immediate survival in the schools.

The national teacher certification examination of primary school mathematics consists of written exams and interview. The subjects of written exams are "comprehensive quality" and "knowledge and ability of education and teaching".

The written examination content of "comprehensive quality” includes five modules: professional idea, teachers' professional ethics, culture accomplishment, the basic ability of teacher. There are many sides of the ability of mathematics teachers, the most basic of which are ability of specialty teaching, science study, lecturing in class and describing with words.

The written examination content of "knowledge and ability of education and teaching" includes seven modules: educational foundations, student direction, class management, subject knowledge, teaching design, teaching implementation, teaching evaluation and reflection.

Interview is the overall examination of students' comprehensive quality. Higher vocational mathematics education curriculum can be divided into three categories: general courses, professional courses, teacher education. These courses basic cover the national teacher certification examination, but there are some shortcomings need to be adjusted. Some courses should be added, the teaching plan and teaching content of some courses should be revised according to the teacher certification examination. In addition, according to the interview subjects, the teachers' education elective courses should be added, such as "speech and eloquence", "etiquette".

2. Streamline specialized courses, increase the general courses

The most important content to strengthen the reform of mathematics teacher education and the teaching mode is to provide normal students with extensive background knowledge. The proportion of general knowledge courses may go up to as much as one third to overall curricular design, in terms of academic credits.

The knowledge of higher mathematics for college students majoring in mathematics do not fall within the scope of the national teacher certification examination. Of course, higher mathematics course may cultivate students' logical thinking ability, mathematical thought method and the method to solve the problem. Therefore, for junior college students, based on the principle of "moderate and enough", we can delete some abstract difficult courses appropriately, and increase some general education courses, such as history, science, etc.

3. Reduce the theoretical lessons, increase the practical hours

Practice is just a necessary condition for forming practical competencies for prospective teachers. In the last decades, though curriculum structure and the teaching mode of teachers education has enjoyed an active exploration and reform, education courses and major courses are also the main focus of the reform, yet the long-standing problem of being rather theoretical and a lack of practice still exists.

However, due to the profound influence of traditional attitudes and behavior, there is still too much emphasis on academic courses with the lack of educational studies, too much knowledge-centered learning and too much stress on theory without enough attention to practice, as well as the course content failing to match the actual curriculum reform in primary and secondary schools. There is a need for an effective balance in the distribution of time given to the learning of theories and knowledge of mathematics and time for practical ideas and teaching strategies so necessary to the beginning teachers' immediate survival in the schools[2].

The written exams of national teacher certification examination demand students' practical ability greatly. The last examination questions are the teaching design and writing respectively, scored 40 points and 50 points, and occupied a fairly large proportion. Whether teaching designs or writing, are practical subjects. The practical hours of the two courses "the elementary school mathematics teaching design and strategy" and "writing" should be increased.

4. Adjust the courses' start dates

According to the national teacher certification examination, the courses' start dates should be taken into account across the board. Some courses' start dates need to be adjusted. There are only six semesters for junior college students at school. In the fifth semester, students will get teacher certification training and education practice, so other courses should not be offered in addition to the teacher certification training courses. The education practice skill training in the fifth semester can bring forward to the fourth semester.

Some courses' start dates lag obviously, such as writing course in fifth or sixth semester, embodied in the written examination of "comprehensive quality", which scores 50 points, accounted for $33.3 \%$ of the total score. Then the writing course should adjust to the third or fourth semester.

\section{B. Reform Teaching Content, to Learn in Order to Practice}

For the teaching method course in teacher education curriculum, we should cut off the vague, useless, old teaching contents, increase specific, informative and lively teaching content. Such as many teaching cases in the elementary school mathematics curriculum and teaching are used before the new curriculum reform. 
At present the elementary schools put to use the new mathematics teaching material after the curriculum reform. In order to adhere to the principle of making study serve the practical purpose, we should combine new teaching material and choose new teaching cases. Thus we should transfer course structure from the over-emphasis on theoretical learning into a combination of theory and practice with equal emphasis.

\section{Innovate Teaching Methods, Linking Theory and Practice}

It is well known that traditional teacher education programs are said to fail in preparing prospective teachers for the realities of the classroom.

To lay a solid foundation and provide more space for students' self-directed learning, the revisions of the educational programs should be performed in line with the ideas of "broad caliber, profound foundation, proficient major knowledge and competitive abilities". Change the mainly teaching way of imparting knowledge, and guide students to self-study.

We live in the era of the network now, and self-educated learners can get abundant invaluable resources by internet quickly. Students can learn by themselves, such as "speech and eloquence", "etiquette”, "literature”, "history”, etc. courses.

\section{Develop Teacher Certification Training Materials and Test-Questions Library Suitable for Local Students}

For junior college students, in conjunction with the education reality of the province, we should develop teacher certification training materials suitable for local students. Special materials for our national teacher certification exams can be adapted appropriately, adding detailed cases of primary school teaching.

The national certification exam questions over the years and the exam simulation questions can be converted into test-questions library for students to practice.

\section{THE REFORM OF THE TALENT TRAINING MODE OF MATHEMATICS EDUCATION PROFESSIONAL}

Although also associated with primary school, the current higher vocational mathematics education professional personnel training, is carried out through the simple way of cooperation among school. The joint training mainly concentrates internship stage in primary school students, that is to say students listen to the teachers of the primary school most of the time, thus learn mainly the teaching skills.

The national certification exam pays more attention to the students' practical ability than students' subject teaching skills, such as class management ability, etc. To change the primary stage to the extensive and thorough stage of cooperation among school, university should strengthen communication and cooperation with primary school. We should promote in-depth cooperation among school on the basis of mutual benefit, thus cultivate high quality normal students.

\section{THE REFORM OF THE TALENT TRAINING EVALUATION SYSTEM OF MATHEMATICS EDUCATION PROFESSIONAL}

There are three main indicators of higher vocational mathematics education professional talent evaluation system in the past: the employment rate of graduates, the performance of graduates, and the evaluation of employer. The quality of talent training is measured through investigating the employment rate of graduates, tracking the performance of graduates, and conducting the research of employer. These three indicators may be gained from students out of the gate of school.

However, to conduct a thorough, systematic and in-depth assessment on the quality of higher vocational mathematics education professional talent training mode is of great significance to the improvement of teaching quality and performance.

Under the background of the national teacher certification examination, in addition to the above three indicators, an important indicator is the pass rate of the national teacher certification examination.

There were 28909 applicants attending the paper tests in the provinces of Zhejiang and Hubei in 2011, the proportion passing the exam amounted to 37.7\%. 9432 applicants attended the interview with a passing rate of $82.9 \%$. Taken together, the passing rate of Zhejiang province was $30.9 \%$, and it was $23.9 \%$ in Hubei province. Thus we can get abundant value information through statistical analyses.

\section{ACKNOWLEDGMENT}

This work is supported by grants of National Nature and Science Foundation of China (No.61463012), Natural Science Foundation of Hainan Province (No.614233, No.114013, No. 613161, No. 613162) ,and Philosophy and Social Science Planning Project of Hainan Province(No. HNSK(ZX)14-168).

\section{REFERENCES}

[1] A. Xiaoying, "Study on several issues of the pre-employment training of the elementary school teacher in the country teacher qualification reformation,” Dalian: Dalian University Master's degree thesis, 2014.

[2] C. Jingan, and M. Zhenwu, “The cross-national comparison of preservice mathematics teacher education and curriculum structure,’Journal of Mathematics Education, vol.3,pp. 119-136, June 2010.

[3] F.A. Korthagen, and J.P.A. Kessels, "Linking theory and practice: changing the pedagogy of teacher education,” Educational Researcher, vol.28,pp.4-17, May 1999

[4] W. Jun. "The influence of national teacher qualification exam on preservice teacher education,” Journal of Higher Education Management, vol. 9,pp. 105-109, March 2015.

[5] D. L. Hammond, "How teacher education matters,”Journal of Teacher Education, vol.51, pp.166-173, March 2000.

[6] K. Zeichner, "Different conceptions of teacher expertise and teacher education in the USA,"Education Research and perspectives, vol.33,pp.60-71, February 2006.

[7] H. Qiuyun, "Higher vocational reform and practice of preschool education professional personnel training mode research,”Xiamen: Xiamen university, 2013. 
[8] K. L. Suat, "Pre-service preparation of mathematics teacher in the Singapore education system,"International Journal of Education Research, vol.7, pp.131-143,2002.

[9] Z. X.Wong, "On the nature of professionalization of mathematics," Journal of Mathematics Education, vol.11,pp. 63-71,2002. 